\title{
Holistic Quality of Life in Women during Natural Perimenopause and Postmenopause
}

\author{
Cárdaba-García Rosa María ${ }^{1 *}$ and Aparicio-García Marta Evelia ${ }^{2}$ \\ ${ }^{1}$ Nursing Department, University of Valladolid (UVa), Spain \\ ${ }^{2}$ Faculty of Psychology, University Complutense of Madrid (UCM), Spain \\ *Corresponding Author: Marta Evelia Aparicio, Faculty of Psychology, \\ University Complutense of Madrid (UCM), Spain.
}

Received: June 23, 2020

Published: August 28, 2020

(C) All rights are reserved by Cárdaba-García Rosa María and Aparicio-García Marta Evelia.

\begin{abstract}
Objective: The goal of the present study was to assess the health status of women during the natural climacteric with respect to physical, mental, and social variables.

Design: It is a descriptive correlational study. Setting 419 perimenopausal women are involved on a voluntary basis. 273 women were premenopausal and 146 were postmenopausal. The tools used were the GHQ-12 General Health Questionnaire, and DukeUNC-11 Questionnaire of Functional Social Support.

Results: It was found that the youngest women tended to suffer from anaemia more often, and that the oldest women suffered from osteoporosis, osteoarthritis and arthritis. It was also found that postmenopausal women had better mental health. Regarding social support, there were no statistically significant differences between the two groups of women. With respect to holistic quality of life, it was found that the youngest women enjoyed better living conditions.

Conclusion: This study provides insight into the health of women during the natural climacteric, and a gender perspective with respect to health research with the aim of removing the possibility of health discrimination by gender.
\end{abstract}

Keywords: Quality of Life; Middle Age; Climacteric; Menopause; Women's Health

\section{Abbreviations}

BMI: Body Mass Index; GHQ: General Health Questionnaire;

HRQOL: Health-Related Quality of Life

\section{Introduction}

Etymologically, the term "holistic" comes from the Greek roots holo- and -ism and refers to "The doctrine that advocates the conception of each reality as a whole distinct from the sum of the component parts". This vision produces an interpretation and a way of approaching reality from a broader and more defined perspective.

The concept of a holistic quality of life refers to understanding health not only as the absence of disease, but also as a high degree of physical, mental and social well-being [1]. This concept is closely related to individual well-being and the presence of physical, psychological and social symptoms. It is based on other psychological concepts, such as subjective well-being and satisfaction with life [2]. Care planning has several dimensions, such as making the person and not the professional the center of the model. Such a model requires that people be recognized as human beings, immersed in a biopsychosocial system of political relations, social and cultural rights, and that the community and the environment be part of a person's reality. A holistic approach responds to people's needs from a multidisciplinary approach $[3,4]$.

Currently, people's health status tends to be measured, according to WHO recommendations, using the concept of health-related 
quality of life (HRQL), which is generally equated not only with health status, but also with functional status and self-care needs. The measurement of HRQL makes it possible to describe a health condition or state, in addition to establishing a prognosis. This measurement is made through the subjective perception of women, which implies for some authors an insurmountable bias, while others extol the virtues of being able to know exactly how women feel. Numerous studies have indicated that mature women achieve worse results on scales that assess quality of life or perceived health than men [5-8]. Life satisfaction is a key factor in HRQL. This is a series of objective and subjective elements that are related to life expectations. When women have high levels of life satisfaction, this generally correlates with a higher HRQL [9-11]. Social support, which includes characteristics such as having people to communicate with and emotional support or displays of affection, love and empathy, has a considerable impact on HRQL [12-14].

Natural climacteric is a period of variable duration that occurs before and after menopause. It includes phases such as perimenopause and postmenopause [15]. Menopause is the definitive cessation of menstruation due to the loss of follicular activity for twelve consecutive months. It is a milestone that occurs in the climacteric around the age of 51, but it is only a specific moment in the entire climacteric process [16]. Perimenopause is a period around menopause, which begins at the same time as the transition to menopause and ends a year after the last menstrual period, which generally occurs in the fourth quarter of a woman's life. Postmenopause is a period that begins from the year of the absence of menstruation and lasts until the end of life $[15,16]$.

The climacteric is a physiological process of aging and maturity, generally accompanied by a set of symptoms that are the consequence of decreased or interrupted ovarian functions that generate a decrease in female sex hormones. The main symptoms that accompany climacteric have been classified according to the areas and functions affected. The most relevant physical symptoms are hot flashes. On the psychical level, menopause is generally associated with mood disorders, but there is a growing scientific literature that relates this symptom to other causes [17-20]. At a social level, climacteric supposes a change in the life of women that passes from the adult stage to the stage of maturity or old age [21-24].

In addition, professionals must participate in promoting selfcare. Personal care refers to the practices or skills that a person, family or group uses to take care of health. These actions are learned throughout life to maintain or improve health and prevent diseases, or treat them, if it occurs $[25,26]$.

Taking into account the previous review, the purpose of the present study was to assess the holistic health status of climatic women in relation to a series of physical, psychological and social variables. Our first hypothesis was that natural perimenopausal women would exhibit a better quality of physical life and a worse quality of psychical life than natural postmenopausal women. The second hypothesis was that natural perimenopausal women would report a subjective perception of increased social support.

\section{Materials and Methods}

Study design

This is a descriptive, correlational, cross-sectional and retrospective study.

\section{Setting and sample}

The sample consisted of 419 volunteers aged between 45 and 64 years. They were divided into two groups: (1) women who met criteria for natural perimenopause and were aged between 45 and 54 years ( $n=273 ; 65.2 \%$ ); and (2) women who meet the criteria for natural postmenopause and age between 55 and 65 years $(n=$ $146 ; 34.8 \%)$. At the time of the study, the women lived in the provinces of Segovia and Madrid, Spain.

The sampling methods were not random through volunteering and snowballing.

\section{Inclusion criteria}

To be a woman; be between 45 and 54 years old (both inclusive) and be natural perimenopausal; being between 55 and 65 years old (both inclusive) and being natural postmenopausal; reside in Segovia or Madrid (Spain); voluntary agree to participate in the study.

\section{Exclusion criteria}

Being a man; be under 45 years old or between 45 and 54 years old (both inclusive) and not be natural perimenopausal; being over 65 years old or between 55 and 65 years old (both inclusive) and not being natural postmenopausal; place of residence outside the provinces of Segovia or Madrid (Spain); do not accept participation in the study; language barrier: not being Spanish-speaking; illiteracy that limits the questionnaire to be self-administered. 


\section{Ethical consideration}

The women were informed of the purpose of the study and their voluntary participation was requested using an informed consent form. The study was approved by a committee of experts in bioethics from the Segovia Health Area on June 19, 2018. Registered number $97 / 2018$. The principles of bioethics are taken into account throughout the research.

\section{Instruments}

The questionnaire prepared for data collection begins by inquiring about socioeconomic variables (age, marital status, number of cohabitants in the home, place of residence, level of education and employment situation).

Their physical health was evaluated by means of the body mass index (BMI), by means of the weight and height declared by the women in the questionnaire, and questions about the presence or absence of common diseases in the general population.

Their mental health was assessed using the 12-item general health questionnaire (GHQ-12) [27]. This is a self-administered questionnaire consisting of 12 items, six positive and six negative, and used as a screening tool to detect morbidity. psychological; Detects non-psychotic psychiatric problems. The total score of the questionnaire is obtained by adding the scores of the 12 items, so that the higher the total score, the worse the health and psychological well-being. The GHQ-12 has a reliability according to different studies carried out with Cronbach's alpha that varies between .82 and $.8624,25$, being in the general population the standardized Cronbach's alpha of .7824 and in those over 65 years of age .9025 . In this case, Cronbach's alpha calculation was .874 (05\% CI: .856 $-.891)$.

In evaluating social employment, the Functional Social Support Questionnaire (DUKE-UNK-11) [28] assesses functional social support, or its perceived quality, and has the advantages of being multidimensional, simple and brief. It consists of 11 items whose responses are measured with the Likert scale that covers scores from 1 to 5 . This is a scale used to represent people's attitudes towards a topic. The overall score ranges from 11 to 55, and scores below 32 points suggest little social support. Cronbach's alpha for internal consistency ranges from .82 [29] to .94 [30], depending on the studies. Note that Cronbach's alpha is different for the two dimensions of the questionnaire. De la Revilla., et al. displays a value of .88 for confidential support and .79 for affective support. In 2012, the degree of reliability of the responses of women in the sample of this study is very high (.936; 95\% CI: .926 - .944).

\section{Data collection and procedure}

The focus of the sample is carried out by contacting groups of women to whom the questionnaire is sent in Google Forms ${ }^{\circledR}$, in order to access a large sample volume.

Data collection takes place from January 7, 2019 to March 31, 2019.

\section{Data analysis}

The statistical analysis was performed with SPSS® software, version 24.0. Chi-square, $\mathrm{U}$ Mann-Whitney, t-tests, and $\mathrm{R}^{2}$ tests were also used.

\section{Results}

The BMI of women was calculated, resulting in an average value of 24.85 and standard deviation 3.67 (95\% CI: 24.94 - 25.20), within a range of between 17.5 and 40.4 , with a median at 24.46 points. It was determined that slightly more than half of the group (55.58\%; 234) have a normal weight. The 35.8\% (150) of participants are overweight and the $7.2 \%(30)$ are obese.

Varicose veins in lower limbs (34.4\%) and Haemorrhoids $(32.7 \%)$ are the most frequent diseases. Also, high cholesterol (28.4\%) and rheumatic disorders (26.5\%). In addition, we can highlight the existence of Depression, Anxiety or some other Psychological disorder (23.2\%) and Pain (between 20.5\% and 22.9\%).

It has been found that the majority of the sample (80.7\%) does not present psychical pathology. But also, that in 12.4\% (52 women) there are indications of possible pathology, along with another $6.9 \%$ (29 women) where there are suspicions of subthreshold pathology, according to the GHQ-12.

The women in the study, generally receive good social support, but it is also true that there are cases with low values in perceived support. The average values (mean and median) on the DUKE scale are high. It can be concluded that the level of support is high globally in the sample, although some women with low values are observed individually. In fact, if the cut-off point 32 is taken as reference in 
Holistic Quality of Life in Women during Natural Perimenopause and Postmenopause

the total score to define that under that value the degree of support is low, there are 73 participants (score $<32$ ) in this subgroup, that is, it can be affirm that $17.4 \%$ (population CI: $13.7 \%-21.2 \%$ ) of these women have a low degree of perceived social support.

Climacteric symptoms that affect quality of life
Some of the symptoms described by the authors during the climacteric are expressed as hot flashes (17.7\% express unbearable) urinary incontinence (12.6\% incidence in the participants), predisposition to vaginal infections (manifested by $23.4 \%$ ), musculoskeletal pain that has $27.1 \%$ incidental in these women, cardiovascular disease (22.1\% of these women) and an increase in other

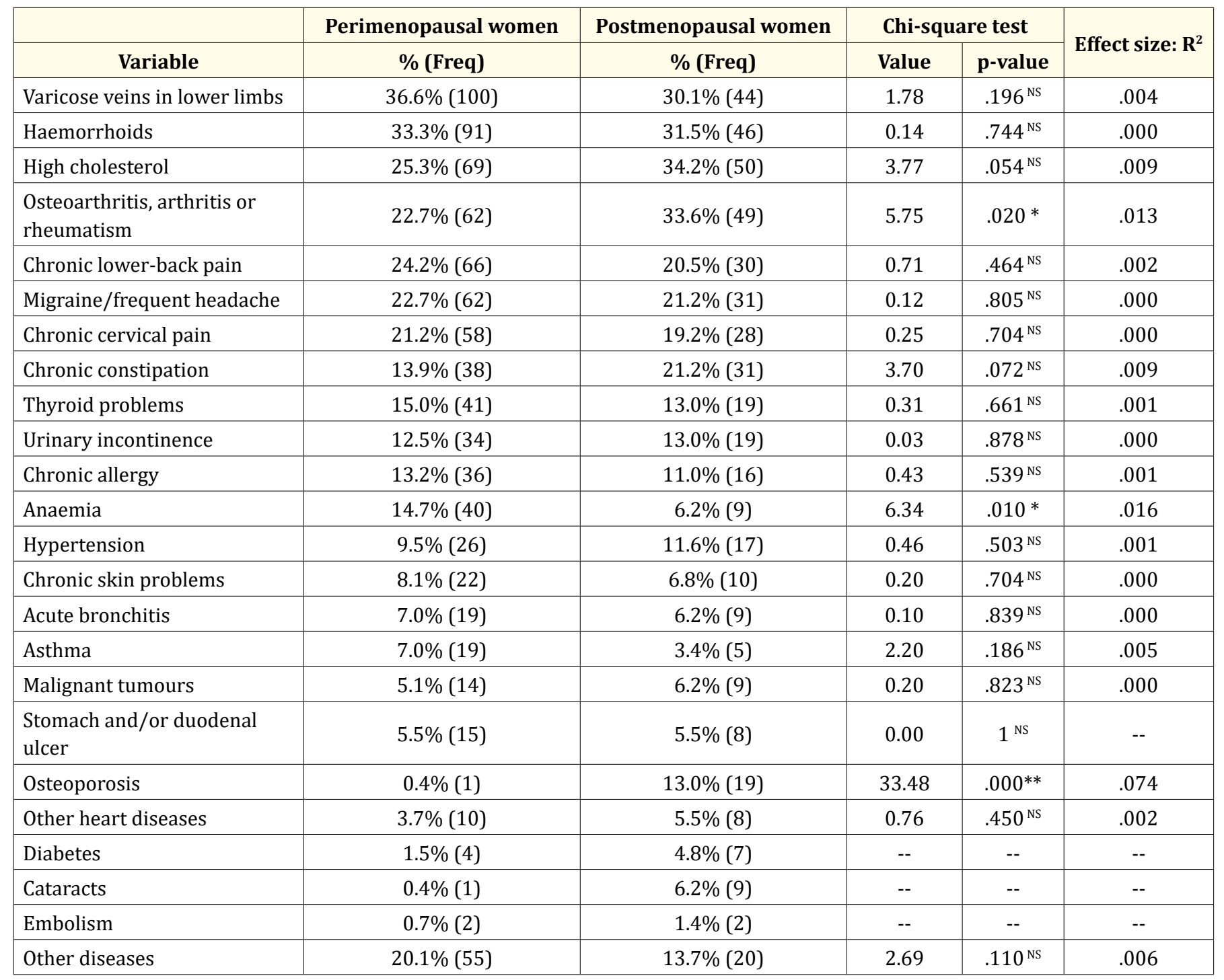

Table 1: Differences in the incidence of physical diseases in perimenopausal and postmenopausal women $(n=419)$.

postmenopausal diseases such as osteoporosis $7.1 \%$ in the sample). The women in the sample also suffer from these and other non-physical symptoms. In the sample of women in the study, up to $15.3 \%$ have severe psychical symptoms.
Fragmented quality of life

Quality of physical life

Regarding the first hypothesis, the results related to physical health indicated that there were no significant differences in BMI 


\begin{tabular}{|c|c|c|c|c|c|c|c|}
\hline \multirow[b]{2}{*}{ Variable } & \multirow{2}{*}{$\begin{array}{c}\begin{array}{c}\text { Perimenopausal } \\
\text { women }(\mathrm{n}=273)\end{array} \\
\text { Average (SD) }\end{array}$} & \multirow{2}{*}{$\begin{array}{c}\begin{array}{c}\text { Post-menopausal } \\
\text { women }(\mathrm{n}=146)\end{array} \\
\text { Average (SD) }\end{array}$} & \multicolumn{2}{|c|}{ U Mann-Whitney } & \multicolumn{2}{|c|}{ Student's t-test } & \multirow{2}{*}{$\begin{array}{l}\text { Effect } \\
\text { size: } R^{2}\end{array}$} \\
\hline & & & Value & p-value & Value & p-value & \\
\hline $\begin{array}{l}\text { GHQ12 - Anxious depressive } \\
\text { symptoms }\end{array}$ & $6.67(3.77)$ & $5.29(3.15)$ & 3.54 & $.000^{* *}$ & 3.78 & $.000^{* *}$ & .033 \\
\hline GHQ12 - Social dysfunction & $5.21(2.23)$ & $4.76(1.83)$ & 2.22 & $.027 *$ & 2.10 & $.037^{*}$ & .010 \\
\hline GHQ12 - Total Score & $11.88(5.44)$ & $10.05(4.51)$ & 3.43 & $.001^{* *}$ & 3.48 & $.001^{* *}$ & .028 \\
\hline
\end{tabular}

Table 2: Differences in psychical health in perimenopausal and postmenopausal women $(\mathrm{n}=419)$.

\begin{tabular}{|c|c|c|c|c|c|}
\hline \multirow[b]{2}{*}{ Variable } & \multirow{2}{*}{$\begin{array}{c}\text { Perimenopausal women } \\
\text { Average (SD) } \\
\end{array}$} & \multirow{2}{*}{$\begin{array}{c}\text { Post-menopausal women } \\
\text { Average (SD) } \\
\end{array}$} & \multicolumn{2}{|c|}{ Student's t-test } & \multirow{2}{*}{$\begin{array}{c}\text { Effect } \\
\text { size: } \mathbf{R}^{2}\end{array}$} \\
\hline & & & Value & p-value & \\
\hline DUKE - Confidential support & $26.48(7.12)$ & $27.94(5.98)$ & -2.11 & $.035^{*}$ & .011 \\
\hline DUKE - Affective support & $14.49(4.13)$ & $15.23(3.44)$ & -1.85 & $.066^{\mathrm{NS}}$ & .008 \\
\hline DUKE - Social support & $40.97(10.86)$ & $43.17(9.00)$ & -2.09 & $.037^{*}$ & .010 \\
\hline
\end{tabular}

Table 3: Differences in social health in perimenopausal and postmenopausal women $(n=419)$.

values between the two groups $(\mathrm{t}=1.07 ; \mathrm{p}=.286)$. Regarding frequent diseases, table 1 shows that there were differences between the two groups regarding: (a) osteoporosis, osteoarthritis, arthritis or rheumatism, and postmenopausal women suffered the majority of such events, although the effect size was small and (b) anemia, with perimenopausal women suffering more from this.

\section{Quality of psychical life}

In the mental health evaluation, the GHQ-12 results indicated that postmenopausal women achieved the best scores (11.88 vs. 10.05), with statistically significant differences and an effect size of .028 (Table 2).

\section{Quality of social life}

Table 3 shows that there were differences between the two groups of women in confidential support and in the total score. Postmenopausal women received the best support.

\section{Discussion}

The purpose of this research was to show the quality of life in a holistic way. According to this concept, it can be affirmed that age and hormonal status influence the quality of life of climacteric women.

Regarding climatic symptoms that affect quality of life, some authors find similar data regarding the presence of hot flashes, urinary incontinence, predisposition to vaginal infections, musculoskeletal pain and osteoporosis [21,22,24,31-33].

Furthermore, some studies have indicated that climacteric women have a lower self-esteem, a greater number of negative life events and a higher prevalence of anxiety and a worse affective life than men of their age, as indicated by Antolín., et al. (2015) and García-Campayo., et al. (2006), among others [31-36].

Regarding the physical quality of life, it seems that the weight is not different depending on the menopausal stage, as stated by Antolín., et al [31]. Yes, there are differences between the two groups in terms of osteoporosis and anemia. Fuentes., et al. (2017), affirm that there are differences regarding osteoporosis in these groups of women, but they explain it by age and not by hormonal defect [33]. Pérez., et al. (2009), also find that perimenopausal women suffer 
more frequently from anemia, which is consistent with this study. Based on the above, it can be determined that part of the first hypothesis of the study is valid [34].

Psychical quality of life is better in postmenopausal women. García-Campayo., et al. (2006) and Sánchez-López., et al. (2012), also find that older women have better psychical health. These data finish confirming the first hypothesis [36,37].

Perceived social support is better in older women. ChinchillaBadilla., et al. (2013) make a global approach to the climacteric and find no differences in terms of social health in these women [23]. On the other hand, other investigations do find this same result [35-37]. Based on this result, the second hypothesis of the study is not valid.

It is common for younger women to have a better quality of life in general $[33,40,41]$, particularly in the physical $[33,40]$, psychical [37,41-43] and social [12,32] aspects.

In Spain, the age of onset of menopause is around 49.3 years, according to the PLENUFAR 5 study by the Association of Spanish Pharmacists (2014). The quality of life of Spanish women decreases when they have some symptoms associated with climacteric, as Borráz-León., et al. [44] also shows. In general terms, all aspects of quality of life are affected, although the psychological domain is the most affected, an aspect also highlighted by Martín., et al [14].

In summary, we evaluated different variables of physical, mental and social health in climacteric women to define their HRQL in a holistic and differentiated way, depending on their climacteric stage $[14,32]$. Physical health, measured by BMI, indicated that there were no differences between the two groups. Regarding chronic diseases, some of the women exhibited significant differences according to the group to which they belonged; however, the effect size was small. Osteoporosis, osteoarthritis, arthritis, and rheumatism were more frequent in postmenopausal women, which is consistent with what previous studies have indicated, since this disease is closely related to aging [34,43]. Perimenopausal women exhibited higher rates of anemia, which, according to other studies, may be the result of menstrual losses, although not exclusively [32]. More studies should be done to determine exactly what factors are associated with the increased prevalence of anemia in younger women, as there are studies that suggest that attributing iron deficiency anemia to menstrual losses may indicate gender bias in the health research $[39,44,45]$.

Statistically significant differences were found in self-perceived mental health. Perimenopausal women generally have poorer mental health, more depressive anxiety symptoms, and perform fewer healthy social functions than postmenopausal women. This result is consistent with those of previous studies that found that mental health improved with age $[20,35,36,46]$. This result could be related to those obtained for social support, given that older women were those who perceived greater social support [37,47].

\section{Limitations of the Study}

This study was not without its limitations. First, the scope of the sample, because the size could be increased and a random sample could be used to generalize the results to the Spanish female population. Second, the use of BMI is not a highly valid method, which could be substituted for another that does not require self-evaluation. Third, there could be confounding variables other than age that have not been accounted for and should be explored. Fourth, the relationships must be detailed in those variables that have statistical significance. Fifth, the cross-sectional design of our study prevents the determination of the time of the variables and the establishment of cause-effect relationships.

\section{Conclusion}

This study contributes to understanding complex processes, such as quality of life, women's general health, and perceived social support. It also makes it easier to meet the individual needs of women during menopause to improve their satisfaction with life. In addition, this analysis can be extended to other areas of women's quality of life, which are addressed in terms of socio-health issues and included in health programs, thus incorporating a gender perspective in health initiatives.

Future lines of work: Our objective is to expand this study to advance a detailed evaluation of other characteristics that may influence women's HRQL, such as gender norms imposed by society.

Additional lines of study will focus on including subjective measures of each woman's specific experiences with her climacteric status, since the presence of symptoms is not always experienced in the same way in all women. It would be appropriate to create a design that combines qualitative and quantitative methodology. 


\section{Conflict of Interest}

We wish to confirm that there are no known conflicts of interest associated with this publication and there has been no significant financial support for this work that could have influenced its outcome.

\section{Bibliography}

1. In: Conferencia Sanitaria Internacional. 1986. Conferencia Sanitaria Internacional. Carta de Ottawa (2020).

2. Capote Bueno I., et al. "Satisfaction of women in climateric stage in brisas del golfo, República Boliviariana de Venezuela (2005-2007)". Revista Cubana de Medicina General Integral (2012): 11.

3. Michaelson V., et al. "The history and promise of holism in health promotion". Health Promotion International (2019): 824-832.

4. Neves E. "The only best way to care for climacteric women". Gynecological Endocrinology (2017): 501-502.

5. Flores Martínez RM and Garay Villegas S. "Calidad de vida y vejez masculina en México”. PRCS (2019): 380-952.

6. Cacchione PZ. "Innovative care models across settings: Providing nursing care to older adults". Geriatric Nursing (2020): 16-20.

7. Estebsari F., et al. "The Concept of Successful Aging: A Review Article". Current Aging Science (2020): 4-10.

8. El Hajj A., et al. "Menopausal symptoms, physical activity level and quality of life of women living in the Mediterranean región". PLoS One (2020).

9. Hoda A and Elazim HAE. "Quality of Life among of Menopausal Women in Saudi Arabia". Jordan Medical Journal (2014): 227242.

10. Dotlic J., et al. "Mental health aspect of quality of life in the menopausal transition". Journal of Psychosomatic Obstetrics and Gynecology (2020): 1-10.
11. Morowatisharifabad MA., et al. "Effects of an educational intervention based on the multi-theory model on promoting the quality of life in postmenopausal women: a protocol". Przeglad Menopauzalny (2019): 153-160.

12. Cuadros JL., et al. "Vital satisfaction and sociodemographic factors in middle-aged women”. Enfermería Clínica (2014): 315322.

13. Doubova Dubova S., et al. "Quality of care and health-related quality of life of climacteric stage women cared for in family medicine clinics in Mexico". Health Quality of Life Outcomes (2010): 20.

14. Martín RM., et al. "Quality of life and menopause: Results of a psychoeducational intervention". Nure Investigación (2014): $1-15$.

15. González Bosquet E and González-Merlo. "Ginecología". Editorial Elsevier: Barcelona (2020).

16. Usandizaga JA and De la Fuente P. "Obstetricia y ginecología”. Editorial Marban. Madrid (2015).

17. Jenabi E., et al. "Correlation between Health Literacy and Quality of Life in Iranian Menopausal Women". Journal of Menopausal Medicine (2020): 34-38.

18. De Souza Santos CA., et al. "Correlation of physical aptitude; functional capacity, corporal balance and quality of life (QoL) among elderly women submitted to a post-menopausal physical activities program". Archives of Gerontology and Geriatrics (2011): 344-349.

19. Greendale GA., et al. "The Menopause Transition and Cognition". The Journal of the American Medical Association (2020).

20. Raglan GB., et al. "Obstetrician-gynecologists' screening and management of depression during perimenopause". Menopause (2020): 393-397.

21. Palacios S., et al. "Health-related quality of life in spanish women during perimenopause and postmenopause. Development and validation of the Cervantes Scale". Medicina Clínica (2004): 240. 
22. Berecki-Gisolf J., et al. "Symptoms reported by women in midlife: menopausal transition or aging?" International Menopause Society (2009): 1021-1029.

23. Chinchilla-Badilla I and Castillo-Vargas A. "Concepts and history of menstrual cessation: a gender-sensitive approach". Revista Costorricense de Psicología (2013): 215-236.

24. Gjelsvik B., et al. "Symptom prevalence during menopause and factors associated with symptoms and menopausal age. Results from the norwegian hordaland women's cohort study". Maturitas (2011): 383-390.

25. Werneke U., et al. "The stability of the factor structure of the general health questionnaire". Psychological Medicine (2000): 823-829.

26. Sánchez-López MP and Dresch V. “The 12-Item General Health Questionnaire (GHQ-12): reliability, external validity and factor structure in the Spanish population". Psicothema (2008): 839-843.

27. Rocha KB., et al. "Propiedades psicométricas y valores normativos del general health questionnaire (GHQ-12) en población general española". International Journal of Clinical and Health Psychology (2011): 125-139.

28. Broadhead WE., et al. "The Duke-UNC functional social support questionnaire. Measurement of social support in family medicine patients". Journal of Medical Case Reports (1988): 709-723.

29. De la Revilla L., et al. "Validación de una escala de apoyo social funcional para su uso en la consulta del médico de familia". Aten Primaria (1991): 688-692.

30. Ayala A., et al. "Propiedades psicométricas del Cuestionario de Apoyo Social Funcional y de la Escala de Soledad en adultos mayores no institucionalizados en España”. Gaceta Sanitaria (2012): 317-324.

31. Antolín Rodríguez R., et al. "Quality of life of women during the climacteric in the Sanitary Area of Vigo". Metas de Enfermería (2015): 63-68.
32. Cárdenas LTG., et al. "Climacteric syndrome in middle-aged women". Revista Cubana de Medicina General Integral (2019): 2-11.

33. Fuentes F., et al. "Facing post menopausal osteoporosis in the gynecological office". Revista Chilena De Obstetricia Y Ginecología (2017): 639-648.

34. Pérez JAM., et al. "Epidemiology of risk factors and symptoms associated with menopause in Spanish women". Maturitas (2009): 30-36.

35. Ornat L., et al. "Sexual function, satisfaction with life and menopausal symptoms in middle-aged women". Maturitas (2013): 261-269.

36. García-Campayo J and Lou-Arnal S. "Affective disorders and gender". Keys in Mental Health (2006): 1-6.

37. Sánchez-López MP., et al. "The Impact of Gender Roles on Health". Women and Health (2012): 182-196.

38. Matud Aznar MP., et al. "Relevance of menopause and social support in health differences between women and men". Universitas Psychologica (2017): 1-11.

39. Vivaldi F and Barra E. "Psychological wellbeing, perceived social support and health perception in older adults". Rev Int Ter Psicol (2012): 23-29.

40. A Silva ., et al. "Quality of life and flexibility assessment of climacteric women after stretching-pilot study". Con Scientiae Saude (2011): 741-747.

41. Freixas Farré A. “So Fresh”. Editorial Paidós: Barcelona (2015).

42. Pérez-López FR., et al. "Assessment of menopause-related symptoms in mid-aged women with the 10-item Cervantes Scale". Maturitas (2013): 151-154.

43. Martínez MD., et al. "Psychosocial factors predicting satisfaction with life in perimenopausal and postmenopausal". Aquichan (2012): 298-307.

44. Borráz-León JI., et al. "Testosterone and mental health: a review". Revista de Psiquiatría y Salud Mental (2015): 44-49. 
45. Howe TE., et al. "Exercise for preventing and treating osteoporosis in postmenopausal women". Cochrane Database of Systematic Reviews (2011).

46. García-Calvente MM., et al. "Gender inequalities in public health research and epidemiology in Spain (2007-2014)". Gac Sanit (2015): 404-411.

47. Sánchez-Sánchez R. "Lo que una mujer no necesita". $A M F$ (2012): 617-625.

\section{Assets from publication with us}

- Prompt Acknowledgement after receiving the article

- Thorough Double blinded peer review

- Rapid Publication

- Issue of Publication Certificate

- High visibility of your Published work

Website: www.actascientific.com/

Submit Article: www.actascientific.com/submission.php

Email us: editor@actascientific.com

Contact us: +919182824667 